\title{
Plan to cull aquarium tuna dead in the water
}

\section{Rex Dalton, Monterey}

Scientists at the Monterey Bay Aquarium in California, one of the world's best-known marine conservation facilities, are struggling to get rid of two huge tuna from the aquarium's main display tank.

Aquarium staff say they tried this summer to kill the healthy, 150-kilogram bluefin tuna (Thunnus orientalis), which rule the 4-million-litre Outer Bay tank. Their attempt to dispatch the fish using anaesthetizing darts has riled conservation experts, who say it may breach accreditation rules for US zoos and aquaria.

Marine-husbandry staff at the aquarium say they wanted to remove the fish because they had become too aggressive, particularly towards hammerhead sharks (Sphyrna lewini), which have been added in recent years to make the facility's marine environment more realistic.

But conservation biologists elsewhere have questioned the attempt at lethal elimination, because bluefin tuna are an important global conservation symbol and are overfished in the wild. "It strikes me as bizarre," says George Amato, director of the science resource centre at the Wildlife Conservation Society in New York, which has its own aquarium. "That would never happen here."

Officials at Monterey Bay say the attempt to have a veterinarian kill the bluefin was approved by its animal-welfare committee. Darting the bluefin was seen as the safest option for staff, and other species in the tank.

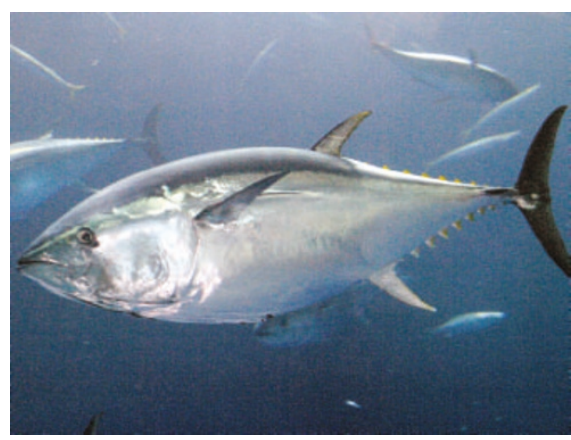

Big problem: Monterey Bay Aquarium staff say their giant bluefin tuna have become aggressive.

The move comes as the aquarium is preparing to introduce a great white shark (Carcharodon carcharias) into the tank. The aquarium has been keeping the shark, a juvenile, under observation in another tank. No white sharks have ever been kept successfully in captivity, scientists say.

Randy Hamilton, the vice-president of husbandry at Monterey Bay, insists that the bluefin are not being removed to make way for the new shark. But he accepts that having them out of the way would cut the likelihood of conflict. The shark could be added to the Outer Bay tank as soon as this week - or not at all, if the team feels that the dynamics in the tank are too complex.

Now in its twentieth year, the aquarium is in the midst of a long-term planning process regarding its exhibits. The board will meet on 17 September to consider a plan for the aquarium, which is run by marine biologist Julie Packard, whose father, computer mogul David Packard, helped to set it up through a charitable foundation.

"Our world is a blend of art and science," says Hamilton."We would like to increase the visitor experience."

Whatever the outcome, the mix of species for the Outer Bay tank has prompted tensions among scientists at the aquarium and at Stanford University's adjacent Hopkins Marine Station. The two facilities jointly support the Tuna Research and Conservation Center, which has pioneered the use of electronic tags to document where tuna and other species roam.

Stanford's Barbara Block, who directs the tuna research centre, is known to be concerned about the aquarium's handling of the bluefin. But she declined to comment on the aquarium's effort to eliminate the fish, saying only that trying to remove large bluefin tuna "is a hard problem".

Conservation authorities say that having plans for removing animals from research or exhibit facilities is required for accreditation by the Maryland-based American Zoo and Aquarium Association (AZA), which has accredited the Monterey Bay Aquarium.

John Hewitt, director of animal husbandry at the Audubon Aquarium of the Americas in New Orleans, who has served on the AZA's accrediting commission, says that, in general, killing an animal to dispose of it "is not an acceptable practice".

Hamilton says he is now working on a new plan to deal with the bluefin.

\section{Rule change set to cost Britain Framework cash}

\section{Jim Giles, London}

British universities say they could be forced to drop out of the European Union's Framework research programme under rules being proposed by the UK government.

The universities say that the government's efforts to change the way it provides their financial support could make it unproductive for academics to seek Framework grants. At the moment, most UK research grants cover only about half a project's true costs, and the main source of the remaining money is block government grants to research institutions. But the block grants have not been keeping pace with the growth in research income (see graph).

So the government announced in July, as part of a ten-year strategy for science, that it would make researchers apply for grants to cover the entire cost of their projects. But

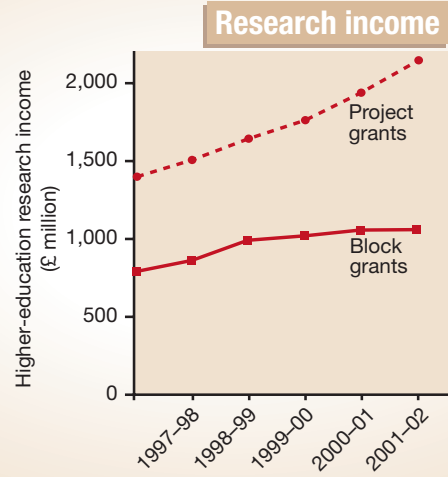

although UK research councils are getting extra funds to help them cope with the switch, the European Commission is sticking to its current arrangements.

Some UK universities might even stop researchers applying for Framework funds because the resulting grants would be unlikely to cover the total project costs, claims Universities UK, which represents most of Britain's institutes of higher education. "This will bite hard on some departments," says Simon Jones, deputy director for research services at the University of Cambridge.

A drop in applications could hit research hard. Britain currently receives some $€ 700$ million (US\$860 million) in Framework funds a year and wins a quarter of all the money allotted to universities by the programme.

Universities want the government to create a new funding stream to help make up the shortfall, which would cost about $€ 100$ million a year. Last month, they sent a paper outlining their ideas to the government.

"We hear what is being said," says

Tino Hernandez, a spokesman for the government's Office of Science and Technology. "But at the end of the day it is up to universities to make decisions about the research they conduct." 